\title{
A SECA NO CEARÁ NAS PINTURAS DE JOSÉ DOS REIS CARVALHO: PINTOR DA COMISSÃO CIENTÍFICA DE EXPLORAÇÃO (1859-1861).
}

Cláudio José Alves

\section{A Comissão Científica de Exploração e o Pintor José dos Reis Carvalho}

A Comissão Científica de Exploração foi criada no IHGB - Instituto Histórico e Geográfico Brasileiro - em reuniões que contavam com a participação do Imperador D. Pedro II. Enquanto as missões estrangeiras que visitavam o Brasil enviavam para fora quase todo material coletado, a Comissão Científica de Exploração seria composta por brasileiros e a maior parte do material iria para o Museu Nacional, criado por D. João VI em 18081. No entanto, D. Pedro II propunha-se também a enviar amostras para museus da Europa, como França, Alemanha, Inglaterra e Áustria. A Comissão foi composta de cinco Seções: Botânica, Mineralogia e Geologia, Zoológica, Astronômica e Geográfica e a Etnográfica e Narrativa de Viagem, esta última seria chefiada pelo escritor Antonio Gonçalves Dias². O professor de Desenho na Escola de Marinha com o posto de tenente, José dos Reis Carvalho, aluno de Jean B. Debret antes mesmo da fundação da Academia Imperial de Belas Artes, foi escolhido para ser o pintor da expedição, considerado bom paisagista, acompanhou as Seções Zoológica e Botânica ${ }^{3}$.

À Comissão Científica de Exploração interessava recolher e descrever a natureza do nordeste em cada uma de suas Seções. José dos Reis Carvalho atendeu a esse perfil. Antes de partir com a expedição ao Ceará, compôs a obra Cerimônia Religiosa, Aquarela/Lápis de Cor/Papel 1853, 13,2 x 16,0 - , nela demonstrou grande habilidade em pintar um ritual religioso. Também em Costumes populares, Aquarela/Lápis de cor/papel

\footnotetext{
${ }^{1}$ M. H. M Ferraz,. As Ciências em Portugal e no Brasil (1772-1822): o texto conflituoso da química. p. 191-195.

${ }^{2}$ R. Braga, História da Comissão Científica de Exploração, pp. 24-32.

${ }^{3}$ R. Braga, op. cit., p. 33. Sobre esse assunto, Renato Braga opõe-se a M. Nogueira da Silva, o autor da obra Biografia de Gonçalves Dias, onde afirma que o pintor José dos Reis Carvalho auxiliara Gonçalves Dias na Seção Etnográfica. Sobre essa questão, embora não relate suas fontes documentais, M. S. Porto-Alegre também afirma que José dos Reis Carvalho acompanhara a Seção Etnográfica. Ver M. S. Porto-Alegre, op. cit., p. 42.
} 
- 1859, 15,3 x 21,1 - observamos vários elementos da cultura local como um animal usado para transporte de carga, um homem com vestuário típico de um vaqueiro e uma mulher que traz na cabeça um tecido bem trabalhado. No quadro Interior de um Rancho, - Aquarela/lápis de cor/papel, 16,0 x 22,8 - é possível identificarmos seu domínio da técnica do desenho e da perspectiva. O rancho parece ser de barro, isto é, de pau-apique, cobre-se com palhas, uma rede indica local propício para descanso. Era indispensável que a Comissão travasse uma relação próxima com pescadores e descrevesse os processos e instrumentos empregados para apanhar o peixe ${ }^{4}$. Assim, das relações travadas com os pescadores, o pintor compôs: Pescaria de Piranha com Jiqui, Aquarela/lápis de cor/papel, 18,1 x 27,6. Nesta obra aparecem modelos das jangadas, arrastões e redes, cabaça, elementos da cultura indígena.

A Comissão, influenciada por um manuscrito do Padre Francisco Teles de Meneses denominado Lamentação Basílica ${ }^{5}$, escolhera o Ceará impulsionada pela crença da existência de riquezas minerais, vegetais, animais e culturais neste local. Dentre as riquezas minerais, esperava-se encontrar fósseis de importância para petrografia e também ouro. Pensando na preparação dessa missão, mais de mil volumes de livros foram adquiridos para a Biblioteca do Museu Nacional. Eles eram relacionados à Geologia, Botânica e Zoologia. Além disso, instrumentos de pesquisa foram importados para servirem nessa empreitada ${ }^{6}$. Partiu no navio vapor Tocantins em 26 de janeiro de 1859 e em 04 de fevereiro de 1859 chegou à Fortaleza. O desembarque ocorreu debaixo de repetidas pancadas de chuvas. De 1859 a 1861 permaneceria, sobretudo, na Província do Ceará, embora visitou também parte do Maranhão, da região Amazônica e do Piauí. Francisco Freire Alemão, chefe da Seção Botânica, informa no seu relatório que o tempo era de florescência e colheram bons exemplares de grande número de espécies que, após preparadas, foram guardadas em caixas de folha de Flandres?

\footnotetext{
${ }^{4}$ Comissão Científica de Exploração, "Instruções para a Comissão Científica encarregada de explorar o interior de algumas províncias do Brasil", in: R. Braga. História da Comissão Científica de Exploração, op. cit., pp. 186-187

${ }^{5}$ Ibid., p. 38.

${ }^{6}$ R. Braga, op. cit., p.39.

${ }^{7}$ F. Freire Alemão, "Relatórios dos Membros da Comissão Lidos no Instituto Histórico e Geográfico Brasileiro”, in: .R. Braga, op. cit., p. 260.
} 
Segundo Francisco Freire Alemão, a época da florescência era a estação pluviosa; nas serras, porém, tanto na estação chuvosa, como na do verão de outubro floresciam os cafezais, os laranjais, e os cajueiros. Nos sertões ocorria também florescência quando as chuvas caíam, mesmo não sendo contínuas, eram suficientes para enfolhar os arbustos e às vezes as caatingas; vinham com as primeiras trovoadas de outubro a novembro, eram as chuvas de rama. Floresciam por esse tempo especialmente o joá, o pereiro, o trapiá e a emburana ${ }^{8}$. José dos Reis Carvalho, considerado pintor de flores, teve farto material para observações, na obra Composição Flor, Aquarela/Pastel/Papel, 39,4 x 27,1 - impressiona pelo tom verde e inspira a vida latente na flor.

Para a Seção Zoológica, a Comissão considerava indispensável desenhar com toda a fidelidade de coloração os animais como peixes e répteis. Isso porque, quando conservados quimicamente para os museus de História Natural, poderiam perder ou mudar suas cores. Os naturalistas viajantes deviam praticar corretíssimos desenhos, fiéis ao colorido. O pintor ilustrou borboletas, na composição Borboletas, Pastel/Papel, 18(?), nesta classe, a dos insetos, poupar-se-ia à iconografia enfadonhas leituras na busca de ligeiras diferenças, mesmo com o uso da terminologia. Diz as instruções: "[...] é indispensável fazê-los desenhar imediatamente com toda a fidelidade de colorido"'. O material botânico, assim como o Zoológico, foi recolhido no Museu Nacional do Rio de Janeiro. O herbário contava com quatorze mil amostras ${ }^{10}$.

\section{A seca na pintura de José dos Reis Carvalho}

Além de outros propósitos, a Comissão visava amenizar os efeitos da seca. A falta de água destruía a vegetação, causava a morte do gado e, como conseqüência, a fome para a população. O artigo doze das "Instruções para a Comissão Científica encarregada de explorar o interior de algumas

\footnotetext{
${ }^{8}$ T.P.S. Brasil, Ensaio Estatístico da Província do Ceará., pp. 165- 166

${ }^{9}$ Comissão Científica de Exploração, "Instruções para a Comissão Científica de Exploração encarregada de explorar o interior de algumas províncias do Brasil” in: R. Braga, op. cit., p. 192.

${ }^{10}$ Ver A. Ducke, Estudos Botânicos no Ceará, vol. 31, no. 2, Anais da Academia Brasileira de Ciências, p. 213
} 
províncias do Brasil" afirma que o flagelo de secas devastadoras deveria ser amenizado com sondagens e abertura de poços artesianos ${ }^{11}$.

Em documento manuscrito, Freire Alemão, chefe da Seção Botânica, trata da questão da seca na Província. Relata a crença dos lavradores, segundo a qual os olhos d'água aparecem após as derrubadas. Expressa sua dificuldade para explicar aos lavradores que, pelo contrário, as derrubadas das matas ocasionava o desaparecimento das fontes, em manuscrito, registra: “[...] mal podia responder, quando queria persuadir de que farias grandes males no país com destruição total de matas, [...] hum delles o desaparecimento das fontes, e diminuição dos rios [...]"12. Os membros da Comissão Científica também publicaram textos sobre a seca. Giacomo Raja Gabaglia também publicou A questão das Secas no Ceara (1861) e Ensaios sobre alguns melhoramentos tendentes à prosperidade da Provincia do Ceará (1877) e Guilherme Capanema publicou Apontamentos sobre secas do Ceará (1878), Seca no Norte (1901) e As secas no Ceará13. No artigo As secas no Ceará, Capanema criticou o comodismo dos lavradores que simplesmente soltavam o gado no pasto, "solta-os e a providência se incumbe de pastorálos e nutri-los". Capanema também tratou da importância das matas. Afirma que o restabelecimento dessas matas implicaria em extinguir os cafezais das serras, na Serra de Uruburetama seria necessário extinguir as plantações de algodão. Capanema termina o artigo afirmando que os hábitos de um povo não se mudam com conselhos, sendo necessário convencimento pela evidência dos fatos, que o cearense, e também o governo, não pensassem que isso era "bobagem de científico"14.

Em MEMÓRIA - Sobre a Conservação das Matas, e Arboricultura como meio de melhorar o Clima da Provincia do Ceará, T. P. S. Brasil afirma que a ignorância, sobretudo, o egoísmo e a indiferença para com as gerações futuras, todos os dias, iam reduzindo e devastando nossas matas. Nas faldas, ou bases das serras e das chapadas, encontravam-se as poucas matas, porque quase todas foram destruídas principalmente para a cultura do

11 Comissão Científica de Exploração, "Instruções para a Comissão Científica de Exploração encarregada de explorar o interior de algumas províncias do Brasil” in: R. Braga, op. cit., p. 201.

${ }^{12}$ F.B. NACIONAL, Francisco Freire Alemão, Será verdade, será possivel, que, durante uma seca, um dos sinais de chuva próxima seja o aumento das águas das fontes? Rio de Janeiro, Junho 1852(?), Mss.:I-28,6,23,548(3), Título 08.

${ }^{13}$ M. S. Porto-alegre, Comissão das Borboletas, op.cit., p. 43.

14 G. S. Capanema, "As secas do Ceará"; in A. A. A. Câmara, Algumas considerações sobre a causa da formação e origem do Gulf-Stream, pp. 3-12. 
algodão que despia todos serrotes e serras mais frescas ${ }^{15}$. Brasil refere-se a Alexander Von Humboldt que na obra Effeitos da destruição das florestas sobre o clima físico, trata da influência da umidade do ar sobre a temperatura e sua importância para o nascer da vegetação ${ }^{16}$. Diz: [...] que todo paiz se torna árido pela desarborização; e todo paiz se torna abundante de água pela arborização ${ }^{17}$.

José dos Reis Carvalho realizou, ainda, a obra Corte de Carnaúba, Aquarela/Lápis de cor/Papel - 1859, 17,9 × 37- A Carnaúba apresentava uso diversificado, seus frutos serviam para alimentação do gado, a folhas serviam para a cordoaria, esteiras, chapéu, cobertura de casas e muitos outros misteres. Francisco Freire Alemão afirma que, as margens do Jaguaribe eram cobertas de verdadeiras florestas de Carnaúbas, que sempre verdes alegravam aquelas paragens ${ }^{18}$. T. P.S. Brasil lamenta o mal uso da planta e seu corte desordenado ${ }^{19}$. José Reis Carvalho retratou-a na pintura Corte de Carnaúba, também retrata seu uso no quadro Moinho de vento feito de carnaúba, no engenho de Cumbe, litoral Aracati de 02 de setembro de 1859, essa obra aparece no catálogo Memória Cearense, publicado pelo Museu Histórico Nacional.

Francisco Freire Alemão referiu-se à dificuldade em convencer o lavrador sobre os danos causados pelo desmatamento e também Capanema tratou da importância de educar o sertanejo para que aprendesse a lidar com a questão da seca, foram inúmeras as sugestões. Do mesmo modo, T.P.S. Brasil mostrou-se preocupado com a arborização e viu como primordial importância convencer povo, fazendeiro e governantes sobre a necessidade de arborização. Esses fatores teriam levado José dos Reis Carvalho a pintar: Aula de Primeiras Letras no Certão, Aquarela/papel, 15,3 x 23,0 .

O sertão não era só uma designação topográfica, mas também o tipo de paisagem hostil ao homem, quente e seca, cheia de penúria e vastidão torna-se expressão metafórica da situação do sertanejo ${ }^{20}$. No quadro Casal em Viagem, Aquarela/Lápis de Cor/Papel - 1859, 20,9 x 35,8 -

\footnotetext{
15 T. P. S., Brasil, Ensaio Estatístico da Província do Ceará, pp. 142-143.

16 T. P. S., Brasil, MEMÓRIA - Sobre a Conservação das Matas, e Arboricultura como meio de melhorar o Clima da Província do Ceará, pp.5-7.

${ }^{17}$ Ibid. pp. 31.

${ }^{18}$ F. F. Alemão, "Relatórios dos Membros da Comissão Lidos no Instituto Histórico e Geográfico Brasileiro", in: R. Braga, História da Comissão Cientifica de Exploração, Ceará, Imprensa Universitária do Ceará, 1962. p. 260.

${ }_{19}$ T. P. S. Brasil. Ensaio Estatístico da Provincia do Ceará, p. 170.

${ }^{20}$ C. Heupel. "O sertão e os motivos de paisagem na literatura ocidental", Rev. Humboldt, pp. 22-25.
} 
o casal parece atravessar o leito de um rio desprovido de água que provavelmente estaria escoando para o vale. A mulher, atrás, leva consigo uma cuia, usa uma roupa de soldado como se estivesse em batalha, parece enfrentar a realidade de modo diferente, possui um semblante menos entristecido do que o homem. Ele carrega peso, leva consigo um pau que lhe serve de apoio para defesa ou guia, usa uma cabaça na cabeça que o protege do sol ardente, uma espingarda serve-lhe de proteção e caça. Os panos em seu braço e uma capa vermelha nos ombros servem de abrigo nas noites frias. Uma palmeira, adiante, indica que caminham em direção à paisagem local não tão seca, parecem cruzar um leito de rio sem água, cujo destino seria o vale logo adiante.

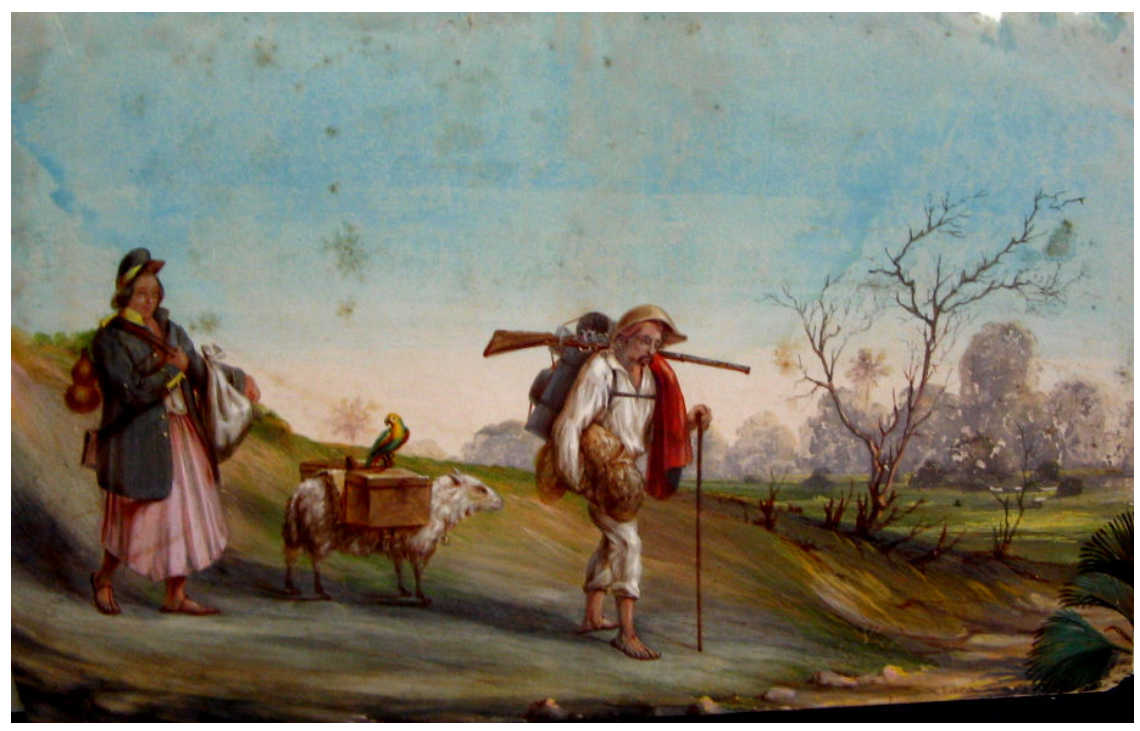

Casal em Viagem - 1859

Aquarela/Lápis de Cor/Papel

$20,9 \times 35,8$

Museu D. João VI. 
Aqui temos uma ação iniciada pelo lado esquerdo em direção ao lado direito da composição. O homem vai à frente. Sem dúvida, nessa composição, observamos elementos da formação clássica de José do Reis Carvalho envolvendo estudos de perspectiva, anatomia e fisiologia das paixões. Está claro que não é uma representação idealizada da natureza típica do movimento neoclássico. A emoção dos personagens representa uma resposta a um ambiente hostil. Em Casal em Viagem, o homem não está em harmonia com a natureza, ou seja, em situação de descanso e paz, o que realmente percebemos é uma resposta às fortes leis naturais, sua fisionomia expressa tristeza diante de uma paisagem composta de galhos secos. Esse sertanejo possui semblante de desânimo, cansaço, dor e fraqueza perante uma natureza pouco amistosa. O casal não, necessariamente, foge de uma condição natural, ou seja, climática, mas, muito provavelmente, de uma condição social, típico do Segundo Reinado (1841-1889), que trazia consigo, além do alto índice analfabetismo, uma estrutura fundiária desigual21. Não repousam, pelo contrário, colocam-se em movimento na busca de superação dos obstáculos comprometedores de suas próprias existências. Nesse quadro não observamos idealização de uma natureza exuberante. Há sim, uma dependência do homem em relação à fatalidade das leis naturais. Enquanto a paisagem nas pinturas históricas era um pretexto menor diante da grandiosidade da cena que se apresentava, a natureza, em Casal em Viagem, tece uma situação de penúria, nela o homem sucumbe, resta-lhe uma saída: migrar.

O quadro Casal em Viagem permite-nos uma breve reflexão sobre a pintura de natureza nacional. Logo após a Independência política de 1822, no Brasil, aparecem as primeiras tentativas de uma representação oficial. Elegiam-se pintores para gravar e enaltecer a nacionalidade, a natureza brasileira tornava-se, no Segundo Reinado, um emblema de nacionalidade. Nesse momento, a natureza foi utilizada como emblema de construção da identidade brasileira. Também na Academia Imperial de Belas Artes a arte estava aliada a um projeto palaciano e pouco atento à tradição local. Como na Europa, a pintura histórica da Academia, fora usada para a montagem de verdadeiras "iconografias nacionais"22. Nesse processo, uma árvore e um

${ }^{21}$ L. M. Schwarcz, "O Brasil Imperial: D. Pedro II e o Século XIX”, in: P. R. Pereira. . Brasiliana da Biblioteca Nacional: guia das fontes sobre o Brasil p. 254-5.

${ }^{22}$ L. M. Scwarcz, "O Brasil Imperial: D. Pedro II e o Século XIX", in: P.R. Pereira. Brasiliana da Biblioteca Nacional: guia das fontes sobre o Brasil, p. 256-8. 
riacho deixavam de ser exclusivamente fenômenos naturais, construía-se uma verdadeira mitologia com relação à natureza brasileira. $\mathrm{O}$ paisagismo que destacava a exuberância tropical pertencia à iconografia nacional. A natureza era convertida em paisagem, em modelo para idealização. A nação aparecia descrita como paisagem de uma sociedade que fazia questão de vestir-se à européia e afastava a imagem da escravidão e da violência ${ }^{23}$. Esse é o caso da pintura de Victor Meirelles de Lima que, na obra A Primeira Missa no Brasil (1860), iniciada em 1859 na Europa, busca retratar para a tela uma determinada concepção contida na famosa descrição de Pero Vaz de Caminha ${ }^{24}$. Em boa parte fora produzida no exterior, em função da política de financiamento, e apresenta uma idealização da paisagem coerente com o olhar de quem descreve de longe, sem contato imediato com a realidade. Se não tínhamos castelos medievais, igrejas da antiguidade ou grandes batalhas a serem lembradas, possuíamos o maior dos rios e a mais bela vegetação tropical ${ }^{25}$.

Embora prevalecesse esse modelo, no qual a natureza tropical exuberante tornou-se ícone de representação da nação brasileira, podemos verificar na obra de José dos Reis Carvalho uma série de monumentos pintados, muitos deles na província do Ceará, em decorrência da Comissão Científica de Exploração, pertencentes ao Museu Histórico Nacional como a Vista da Matriz e do Santo Cruzeiro na Capital - Ceará, Aquarela/Pastel/Papel /1859, 24,9 x 41,2 - dentre outras.

Luiz Gonzaga-Duque, situa-nos perante a questão da criação de uma iconografia nacional na obra $A$ arte Brasileira, publicada em $1888^{26}$. Refuta uma arte baseada na imitação dos antigos. Para ele estudos longos sobre as questões raciais, históricas e sociais, além de uma fidelidade às suas próprias idéias, sentimentos e emoções dariam ao artista elementos para independência do pensar e agir ${ }^{27}$.

José dos Reis Carvalho, em oposição a um modelo de representação vigente, cria-nos uma paisagem mais próxima da realidade local. Quase esquecido, recordou-nos os esforços de nossos antepassados

\footnotetext{
${ }^{23}$ L. K. M. Shwarcz, A natureza como paisagem: imagem e representação no Segundo Reinado. pp. 8-11.

${ }^{24}$ Ibid., p. 25.

${ }^{25}$ L. M. Scwarcz, “O Brasil Imperial: D. Pedro II e o Século XIX”, in: P. R. Pereira (org.) Brasiliana da Biblioteca Nacional: guia das fontes sobre o Brasil, p. 257.

${ }^{26}$ T. Chiarelli, "Gonzaga-Duque: A moldura e o quadro da arte braslieira”. In: A arte Brasileira/Luiz Gonzaga Duque Estrada. pp. 15-20.

${ }^{27}$ Ibid., pp. 26-38.
} 


\section{em criar aqui uma paisagem civilizada, onde homem e natureza sobrevivem a uma dialética feroz de sobrevivência.}

\section{Bibliografia}

Alemão, F. Freire. "Relatórios dos Membros da Comissão Lidos no Instituto Histórico e Geográfico Brasileiro", RIHGB, 24, Suplemento (1861): 752, 759,764 e 765. in: R. Braga, História da Comissão Científica de Exploração, Ceará, Imprensa Universitária do Ceará, 1962.

Alfonso-Goldfarb, A.M. \& C. A. Maira, orgs. História da Ciência: o Mapa do Conhecimento. Rio de Janeiro: Expressão e Cultura; São Paulo: Edusp, 1995.

Braga, Renato. História da Comissão Científica de Exploração, Ceará, Imprensa Universitária do Ceará, 1962.

Brasil, T. P. de S., Ensaio Estatístico da Província do Ceará, Tomo I, 12. ed. 1863; reimpressão facsimilar, Fortaleza, Fundação Waldemar Alcântara, 1997.

Brasil, T. P. de S., Memória - Sobre a Conservação das Matas, e Arboricultura como meio de melhorar o Clima da Província do Ceará, Typographia Brasileira, Fortaleza, 1859; reimpressão fac-similar, Fortaleza, Fundação Waldemar Alcântara, s/d.

CAPANEMA, G. S. de "Relatório do Sr. Dr. Capanema Lido na Sessão do IHGB, de 4-12-1857", RIHBG, 20, (1857), pp. 63 a 67, in: R. Braga. História da Comissão Científica de Exploração. p. 115.

Capanema, G. S. de. "As secas do Ceará"; in: A. A. A. Câmara, Algumas Considerações Sobre a Causa da Formação e Origem do Gulf-Stream, Museu Nacional, Rio de Janeiro, 1954.

Chiarelli. T. "Gonzaga-Duque: A Moldura e o Quadro da Arte Brasileira". In: A Arte Brasileira/Luiz Gonzaga Duque Estrada. Campinas: Mercado de Letras, 1995.

Comissão Científica de Exploração. Trabalhos da Comissão Científica de Exploração. Tipografia Universal de Laemmert, Rio de Janeiro, 1862. in: R. Braga, Renato. História da Comissão Científica de Exploração. Fortaleza, Imprensa Universitária do Ceará, 1962.

Fundação Biblioteca Nacional, Francisco Freire Alemão, Será verdade, será possível, que, durante uma sêca, um dos sinais de chuva próxima seja o aumento das águas das fontes? Rio de Janeiro, Junho 1852(?), Mss.: I-28, 6,23, 548 (3), Título 08.

HeupeL, C. " O sertão e os motivos de paisagem na literatura ocidental”, Rev. Humboldt, No. 12, (1965): 22-25.

PORTO-ALEGRE, M. S. Comissão das Borboletas - A Ciência do Império, entre o Ceará e a corte (1856-1867), Coleção Outras Histórias (17), Fortaleza, Museu do Ceará, 2003.

Schwarcz, L. K. M. "O Brasil Imperial: D. Pedro II e o Século XIX”, in: P. R. Pereira (org.). Brasiliana da Biblioteca Nacional: guia das fontes sobre o Brasil. Rio de Janeiro: Editora Nova Fronteira, 2001.

Schwarcz, L. K. M. "A natureza como paisagem: imagem e representação no Segundo Reinado", Revista USP, São Paulo, no. 58, (2003, junho/agosto): p. 6-29.

Schwarcz, L. K. M. "O Olhar Naturalista: entre a ruptura e a tradução", in: Revista de Antropologia. 35, (1992): pp. 149-167. 